\title{
Integrate Medical Humanities in Medical Education: Take the Example of Histology and Embryology Teaching
}

\author{
Shi Min ${ }^{1, ~ a ~}$, Wang Min ${ }^{1, ~ b}$, Zhao Sha ${ }^{1, ~ c}$, Ma Simin², d, * \\ ${ }^{1}$ Medical College, Xi’an Peihua University, Xi’an, Shaanxi \\ ${ }^{2}$ Xi’an Jiaotong University Health Science Center, Xi'an, Shaanxi \\ a 1243838277@qq.com, b397718295@qq.com, ${ }^{\mathrm{c}} 526822263 @ q q . c o m,{ }^{\mathrm{d}}$ 2326044176@qq.com \\ *corresponding author
}

Keywords: Education of medical humanities, Doctor-patient conflict, Humanistic spirit, Histology and Embryology

\begin{abstract}
Medical science is the science that studies life. The essence of medical science is the combination of medicine and humanities. The medical humanistic education focuses on the people-oriented education concept, emphasizing the integration of medical science and humanities, and guiding the medical behavior of the healers with the values of humanistic spiritual values. In this paper, taking Histology and Embryology as an example, on the basis of analysing the characteristics of the Histology and Embryology curriculum, we discussed the importance of integrating medical humanities education in the teaching of Histology and Embryology, and elaborated our own practice plan of integrating medical humanities education into the teaching of Histology and Embryology, and summed up some of our own experiences and understanding with a view to providing reference and practical experience for medical education under the new model, promote the organic integration of medical science and humanities.
\end{abstract}

\section{Introduction}

With the continuous improvement of current medical equipment and medical technology, we have made greater progress in curing the difficult disease. Today, however, the frequent conflicts between doctors and patients and injuries to medical staff are still a "characteristic" social event in the current context. The reform policy of public hospitals has been implemented for eight years. The government has also invested huge financial resources. However, the sharp contradition between doctor and patient has not yet improved. The doctor-patient relationship arises when the patient is physically and psychologically most vulnerable and needs special comfort. In a sense, it should be said that it is the warmest and most kind relationship between humans. However, the contradiction between doctor and patient is still so acute. Why is the hospital constantly advocating the leading technology and service-oriented, but in the end it is the frequent occurrence of vicious medical incident? The contradiction between doctor and patient is inextricably linked to the lack of knowledge of national health. But in fact, there is a "medical ethics are lost" behind the doctor-patient contradiction. The essence is the lack of humanistic spirit at the medical levels[1]. From the perspective of education, the "doctor-patient conflict" is a realistic reflection to the moral quality of doctors, and it is also a reflection to the effectiveness of medical humanistic education.

\section{The relationship between medical humanistic education and the nature of medical science}

Medical science is about the discipline of life and it is academics about humanities. Medical science not only concerns physical health, but also cares about mental and psychological health. The essence of medical science is the combination of medicine and humanities. The traditional medical model focus on disease and aims to relieve the patient's pain. With the formation of a "biological-psychological-social" modern medical model, people's demand and expectations for medical services have been continuously improved, and patients' understanding of medical care has 
become more emotional and caring. This will serve as a warning to medical colleges to strengthen the cultivation of medical students' humanistic qualities. At present, however, the medical colleges and universities are not optimistic about the current status of cultivation of medical humanities in China. The doctor maybe ignore the basic dignity of patients and deviate from the humanistic nature of medical science. The cultivation of humanistic spirit allows doctors to use medical knowledge to relieve patients' pain, treat patients with kindness, strengthen communication with patients, respect patient's wishes, and establish good communication with patient's family to achieve harmony between doctors and patients. Medical humanity is the soul of medicial science. So it is essential that strengthening medical students' humanistic literacy, and it is an inevitable requirement for medical education to adapt to the modern medical treatment.

\section{The Importance of Integrating Medical Humanistic Education into Histology and Embryology Teaching}

\subsection{Medical humanistic education is a natural component of medical science}

Ba De-nian, the member of China Engineering Academy, expounded his understanding of the nature of medicine: "Scientific truth-seeking, the humanity is good, art is beautiful, and medical science is the perfect combination of science and art." Therefore, medical education is a great cause that integrates the truth of science and humanity. Medical education should have two aspects. On the one hand, through professional medical knowledge education, students should become good doctors with good medical skills. On the other hand, through medical humanities education, medical students should be promoted to humanities and medical science and be the best doctor. Medical practice shows that the removal of patient suffering requires rich knowledge and superb professional skills. However, good humanistic awareness and ability have become the most important aspect to treat and save people. Medical staff lacking humanistic care are prone to conflict with patients. Only by strengthening the training of medical humanities can we become a qualified doctor. This is not only an inevitable trend of modern medicine, but also an inevitable requirement of social development.

\subsection{Medical Humanities Education Contains “Inherent Deficiency”}

First of all, the overall students' source quality after the expansion of enrollment in higher education is declining. College students' weak awareness of behavioral norms, coupled with the fact that medical students emphasize science, there are inherent "innate" deficiencies in humanistic qualities; Secondly, with the traditional medical education curriculum in China, education in medical expertise and skills is over-emphasized, but the cultivation model of humanisty is still in the process of exploration, which restricts the improvement of medical students' humanistic quality and medical humanistic level. In addition, the medical humanities curriculum in China is an selective course outside the non-professional curriculum. The doctor-patient relationship is an important knowledge point in the medical humanities curriculum. This non-parallel relationship leads to knowledge "breaking" between medical humanistic education and professional education[2]. Therefore, how to strengthen medical students' humanistic qualities as early as possible, especially in the basic medical education stage of medical students.It highlights the importance of cultivating medical students' humanistic qualities. This is a very important issue for medical students who have just entered the college[3].

\subsection{The Necessity of Integrating Medical Humanistic Education into Histology and Embryology Teaching}

The Histology and Embryology is a medical morphology course. This course is usually set up in the first semester of freshman year, and it is one of the earliest medical students who came into contact with medical education after entering the college. The basic knowledge of the normal human body's microscopic structure and the new individual process is studied in Histology and Embryology. The research involved various medical humanities knowledge and ethical issues, such 
as the acquisition of human specimens and the source of various malformed fetal specimens. First of all, students should realize that every specimen of embryo has been a life. They should guide them to have a sympathetic heart for the malformed embryo specimens, infiltrate the ethics of respect for life into professional knowledge, and extend humanistic care to all aspects. This will not only deepen students' understanding of theoretical knowledge, but also guide students to establish correct values and promote the healthy growth of students. This has important guiding significance for them to adopt the humanistic spiritual value concept to solve clinical problems in the future.

\section{Status Quo of Medical Humanities Education in China}

Medical college pay great attention to medical humanities education abroad. For example, the proportion of medical humanities courses in the United States is $20 \%$, but the proportion of medical humanities courses in China is only $7 \%$ to $8 \%[4]$, and there is a big gap between China and abroad. Although most medical college have drawn up the goal of enhancing the cultivation of humanistic literacy for medical students, due to heavy professional courses, humanities courses are mostly conducted as selective courses, resulting in the marginalization of the humanities curriculum. The lack of attention to the humanistic curriculum in medical college directly leads students to neglect the learning of the course. Humanities cannot be equated with professional courses. Therefore, the students' attitudes toward learning are not correct, and there are phenomena such as playing mobile phones and skipping classes in the humanities classroom. Moreover, the medical humanities curriculum is very irrational and the teaching methods are simple. The courses are opened later and they are all traditional theoretical teaching. Students cannot access to concrete real cases. It has led to a serious disconnect between medical humanistic education and clinical practice. Students are less interested in learning humanistic knowledge[5]. In addition, humanistic education has not yet formed a good regular mechanism, and humanistic curriculum education is poorly targeted and practical. Even if students are able to carry out course studies, they can only understand or become familiar with some relevant normative contents, but they will not "sense, receive, and internalize" from their own needs.Therefore, from the beginning of medical students' exposure to medical education, we should gradually integrate medical knowledge and humanistic knowledge and extend the cultivation of humanistic literacy to various courses and stages of medical professional education. To permeate the humanities throughout the process of cultivating medical application-oriented comprehensive talents, so that the cultivation of medical and humanistic qualities forms a regular mechanism.

\section{The Practice of Integrating Teaching of Histology and Embryology into Medical Humanities Education}

\subsection{Adjust course settings and implicitly increase medical and humanistic education content}

Although medical college have reached a consensus on strengthening medical students' humanities education for a long time, they have not yet achieved a fundamental change. This is mainly because professional courses have the large proportion. Lack of college hours seems to be the biggest obstacle to medical humanistic education[6]. Therefore, if we want to cultivate medical students with excellent humanities quality, we must set up a reasonable curriculum system. First of all, the medical humanistic education runs through the professional class teaching, so that professional class teaching not only imparts professional knowledge, but also more importantly enhances the students' humanistic spirit and professional quality. Professional instructors invited clinical workers in affiliated hospitals or teaching hospitals. Their clinical experience and cases are the best teaching materials. Secondly, humanistic quality education is permeated in public courses and humanities selective courses are appropriately added. The use of selective courses enables medical students to understand the importance of humanistic education from multiple perspectives and to fully nurture and enhance their own humanistic qualities. Third, integrate humanistic quality education into clinical teaching. When medical students are in contact with patients during clinical 
internships, teachers integrating humanistic concepts with clinical examples will surely achieve a multiplier effect. The teacher of Histology and Embryology can invite the clinician and ideological and moral teacher to prepare lessons collectively, and analyze the humanistic and ethical issues involved in the teaching of Histology and Embryology in the form of joint discussions and brainstorming, seamlessly link professional knowledge with humanistic content, and infiltrate humanistic knowledge into professional knowledge class.

\subsection{Raising the Medical Humanities Quality of Histology and Embryology Teachers}

As all medical college only pay attention to the strength of professional teachers, the humanities teachers are seriously inadequate, resulting in a serious lack of medical students' humanistic spirit. Improving the humanistic qualities of professional instructors can effectively compensate for the lack of humanities teacher and limited humanities curriculum. It can also achieve the horizontal penetration of humanistic education into professional knowledge and embody the Overall System Concept of "Heaven and Man". Medical students are most in touch with professional teachers in the stage of medical education. Teachers with good medical ethics and medical humanities will have a profound influence on medical students. A teacher of Histology and Embryology is the first medical professional teacher faced by medical students. Their performance directly affects the medical students' first impression of the medical profession, so the Histology and Embryology teachers must have high humanistic qualities.

First of all, the Histology and Embryology teachers should improve their own humanistic qualities and continue to improve the humanistic knowledge reserve. Second, Chinese traditional culture was infiltrated into teaching and traditional medical ethics was used to enhance medical students' humanistic qualities. Students can master professional knowledge while also thinking about the medical ethical issues, such as ethical content in gametes donation and surrogacy in assisted reproductive technology. From the examples to promote students to use the ethics concept to analyze problems and solve problems. Finally, we regularly carry out humanities education and training conference to let students know how to care and respect patients.

\subsection{Elaborately design teaching content and organically integrate humanistic medical concepts}

Given the disciplinary characteristics of Histology and Embryology, that is, the many concept, the boring, abstract and difficult to understand content, coupled with the previous "cramming" teaching methods, resulting in lacking of interest in student learning. Focusing on subject research hotspots, through meticulous instructional design, medical humanistic knowledge and concepts are penetrated in boring professional content, allowing students to form a good humanistic quality and professional ethics in professional knowledge learning. When explaining the macrophage in connective tissue, some social hotspots can be introduced. For example, a migrant worker has been exposed to a dusty environment for a long period of time due to occupational reasons. He was diagnosed as "pneumoconiosis" by a number of hospitals and could not apply for an occupational disease appraisal from an authoritative organization. He repeatedly complained to the relevant departments, the local occupational disease prevention and control institute even made a diagnosis of "tuberculosis". The 28-years man disregarded the doctor's advice and insisted on "opening the chest and examining the lungs". He uncovered the lies with frustration, which caused a strong reaction from various sectors of society. This event allows students to better understand the morphological features and powerful phagocytosis of macrophages. At the same time, let students pay attention to the people's livelihood issues, deeply feel the tragic experience of grassroots people, and guide students to the correct values, and then trigger students to discuss the relevant knowledge of professional ethics.

\subsection{Enrich medical students' after-school life and create a good environment for humanistic education}

A good campus cultural environment will enable students to integrate humanistic education into the students' after-school life in a subtle manner while learning medical and cultural knowledge, 
which will have a positive impact on students. Universities should make full use of academic exchanges, campus cultural activities, etc., organize new students to participate in the swearing-in ceremony, and invite teachers to preach and teach. In addition to explaining medical expertise, they should also include humanities and medical ethics. It is also possible to carry out professional ethics and humanistic accomplishments through the Internet and campus media, promote the spirit of medical humanities, and use interactive platforms such as WeChat and QQ to express their views on humanistic education and professional ethics. In addition, students can also visit life significance exhibition hall, or participate in the Red Cross Society after school hours, and integrate medical and humanistic content into the activities so that students can gradually cultivate and nurture humanistic qualities.

The emergence of new medical models has brought medicine back from the natural sciences to the humanities. S E Luria, winner of the Nobel Prize in Physiology and Medicine, said: "Medical science is essentially dual in nature. It is both a natual science and a humanitic science, it needs nourishment from the humanities." Therefore, compared with other sciences, medical science is the most humanistic discipline. The Histology and Embryology curriculum is set up in the first semester of freshmen, its teaching content is abstract and boring. In order to improve the teaching effect, at the same time, it helps students to develop medical humanities as soon as possible, and integrates humanistic education into professional classes such as Histology and Embryology. It plays an important role in cultivating comprehensive application-type medical talents of "science brain, humanitic heart, with technology and temperature” in China.

\section{Acknowledgements}

This paper is part of the 2017 Xi'an Peihua College's Key Teaching Reform-Innovation on the "CBL+PBL+TBL" Triple Teaching Method with Module Integration in the Embodied Cubical Stereo Teaching Model, NO: PHZ1703.

\section{References}

[1] Feng Jun, Yi li-hua, Ding Zhong, et al. Discussion of hospital humanistic construction in the improving of doctor-patient relationship[J]. Modern Hospital Management, 2018, 16(1) : 90-92.

[2] Wang Chao. The Examination and Reconstruction of Medical Ethics Education in the Background of “Clinicians-patient Conflict”[J]. Ethical research, 2018, 39 (1): 100-105.

[3] Yang Yong-li, Wang Jin-sheng, Wen Kai. Development Dilemma and Outlet of Humanistic Quality Education in Medical Universities and Colleges[J]. Chinese Medical Ethics, 2017, 30(8) : 1018-1024.

[4] Deng Lu-lu, Liu Shao-peng. Study on the Problems of Standardized Patient in Practice Teaching of Internal Medicine Nursing[J]. Chinese Medicine Modern Distance Education of China, 2017, 15(7): 3-5.

[5] Bi Jing, Wang Gao-feng. Research on the Problems and Development Path of Humanistic Quality Training for Medical Students[J]. Journal of Jinzhou Medical University (Social Science Edition) , 2018, 61(1): 32-34.

[6] Luo Jun, Li Yan, Wang Cheng, et al. The Organic Combination of Humanities Education and Professional Education in Biochemistry Online Courses[J]. Health Vocational Education, 2018, 4(36): 3-5. 